\title{
DE TODOS NÓS: REFLEXÕES SOBRE PROCESSOS EM EQUIPE NA CRIAÇÃO DA MICROSSÉRIE A PEDRA DO REINO, DIRIGIDA POR LUIZ FERNANDO CARVALHO
}

\author{
FROM ALL OF US: REFLECTIONS ON TEAM PROCESSES IN THE \\ CREATION OF THE MICROSERIES THE KINGDOM STONE, DIRECTED BY \\ LUIZ FERNANDO CARVALHO
}

Tailze Melo

IEC-PUC-Minas

\begin{abstract}
Resumo: A reflexão que nos move se volta para o lugar do processo de criação pensando dentro das singularidades dos grupos criativos. Para isso, iremos tomar os registros produzidos pela equipe criativa que participou ativamente do processo de criação da microssérie A pedra do reino, exibida na TV Globo, em cinco capítulos em 2007. Importa, portanto, pensar como, em meio a um processo de natureza coletiva, podemos também localizar a singularidade de um pensamento que, de certo modo, orienta toda a esfera dialógica. Estamos aqui nos referindo ao projeto pessoal e artístico do diretor Luiz Fernando Carvalho que se debruçou sobre o projeto estético de bases armoriais de Ariano Suassuna, autor do romance homônimo que originou a microssérie.
\end{abstract}

Palavras-Chave: processo criativo, grupo criativo, crítica de processo, armorial.

Abstract: The reflection that moves us turns to the place of the creation process thinking within the singularities of the creative groups. For this, we will take the records produced by the creative team that participated actively in the process of creating the microsite The stone of the kingdom, shown on TV Globo, in five chapters in 2007. It is therefore important to think how, in the midst of a process of nature collective, we can also locate the uniqueness of a thought that in a sense guides this whole dialogical sphere. We are referring here to the personal and artistic project of the director Luiz Fernando Carvalho, who focused on the ethical and aesthetic project of Ariano Suassuna, based on armorial bases.

Keywords: creative process, creative group, process criticism, armorial. 
Uma palavra, sua diminuta extensão e sua expandida rede de sentidos: nós. Monossilábica é proferida em apenas uma abertura dos lábios. Apesar da grafia e pronúncia simples, essa palavrinha constrói em torno de si uma complexa e significativa rede semântica que, aqui, será tomada como um preâmbulo para a reflexão que se pretende fazer acerca da ideia de criação, recortada no âmbito de um determinado grupo criativo. Nesse caso, a equipe de artistas e profissionais de várias áreas que participaram da construção coletiva da microssérie $A$ pedra do Reino, dirigida por Luiz Fernando Carvalho ${ }^{1}$.

1 Luiz Fernando Carvalho é cineasta e diretor de televisão, nascido na cidade do Rio de Janeiro. Sua trajetória no campo do audiovisual é marcada pelo estreito diálogo com a literatura brasileira. Seus primeiros trabalhos no núcleo de teledramaturgia da Rede Globo foram como assistente de direção das minisséries O tempo e o vento (1985) e Grande Sertão Veredas (1986). Ainda na década de 1980, escreveu e dirigiu o premiado A espera, adaptação do livro Fragmentos de um discurso amoroso, de Roland Barthes. Seu grande des taque no cinema foi o filme Lavoura Arcaica (2001), baseado no livro homônimo do escritor Raduan Nassar. O filme foi exibido em diversos festivais nacionais e internacionais, ganhando importantes prêmios por este trabalho. No mesmo ano em que filmou Lavoura Arcaica, dirigiu a minissérie Os maias, adaptada do romance de Eça de Queiroz. Em 2005, dirigiu a microssérie Hoje é dia de Maria. Em 2008, foi exibida a microssérie Capitu, baseada na obra de Machado de Assis. Em 2013, foi responsável pela direção geral da série Correio Feminino, baseada em textos de Clarice Lispector. No mesmo ano, escreveu e dirigiu o especial de fim de ano Alexandre e Outros Heróis, adaptação de dois contos de Graciliano Ramos: O olho torto de Alexandre e A morte de Alexandre. Dentre as muitas novelas que dirigiu na TV Globo, destaca-se Meu pedacinho de chão (2014) por sua linguagem inovadora e soluções plásticas inventivas como, por exemplo, os figurinos feitos de materiais reciclados. Carvalho atuou como diretor de três produções televisivas baseadas em textos de Ariano Suassuna, mantendo durante a realização desses trabalhos um diálogo permanente com o escritor. Duas delas, Uma mulher vestida de sol (1994) e Farso da boa preguiça (1995), foram adaptadas de peças teatrais. Em 2007, dirigiu a microssérie A Pedra do Reino, tradução do romance Romance d'A Pedra do Reino e o Príncipe do Sangue do Vai-e-Volta, com cinco episódios e cerca de quatro horas de duração.
Voltemos aos nós e suas inquietantes variações de sentidos. No território gramatical, como pronome pessoal da primeira pessoa do plural, remete ao lugar da coletividade, da autoria colaborativa, da intertextualidade, do hipertexto. Processos criativos que se entrelaçam no jogo entre o eu e o outro, resultando em nós dos mais variados tipos: cego, górdio, embrionário. Assim, existem nós que encurtam, unem, marcam, sufocam. Nó que não se pode desatar é nó górdio. Nó difícil, mas não impossível de ser desfeito, é nó cego. Nó que dá origem a outros nós é nó embrionário, tipo de nó que pulsa nas interações criativas.

Todo esse contexto variado e rico de sentidos, evocado pela palavra nós, nos move para o lugar do processo de criação pensando dentro das singularidades das comunidades criativas ${ }^{2}$ a partir de documentos de processos que trazem as experimentações e registros também de uma coletividade. Para isso iremos tomar os registros produzidos pela equipe criativa que participou ativamente do processo de criação da microssérie $A$ pedra do reino, exibida na TV Globo, em cinco capítulos em 2007. Por ocasião do lançamento da microssérie, foi publicado um conjunto de seis livros de processo $^{3}$ do diretor Luiz Fernando Carvalho, sendo cinco deles de anotações de Carvalho e um dedicado a notações de muitos membros da equipe.

2 Cecilia Almeida Salles, em seu livro Processo de Criação em Grupo: diálogos, cita a definição de Shelemay (2011) sobre comunidades musicais, expandindo seu sentido para grupos criativos de linguagens diversas. Uma comunidade criativa seria definida basicamente por afinidades, desejos individuais, associações de interesse comum e sentido de pertencimento.

3 Optamos pelo termo livro de processo para acompanhar a terminologia utilizada nos próprios volumes. No entanto, poderíamos usar qualquer outro que apontasse para a ideia de registro do percurso criativo da microssérie: caderno de filmagem, sketchbook, dossiê, diário de criação, dentre outros dessa mesma rede semântica. 


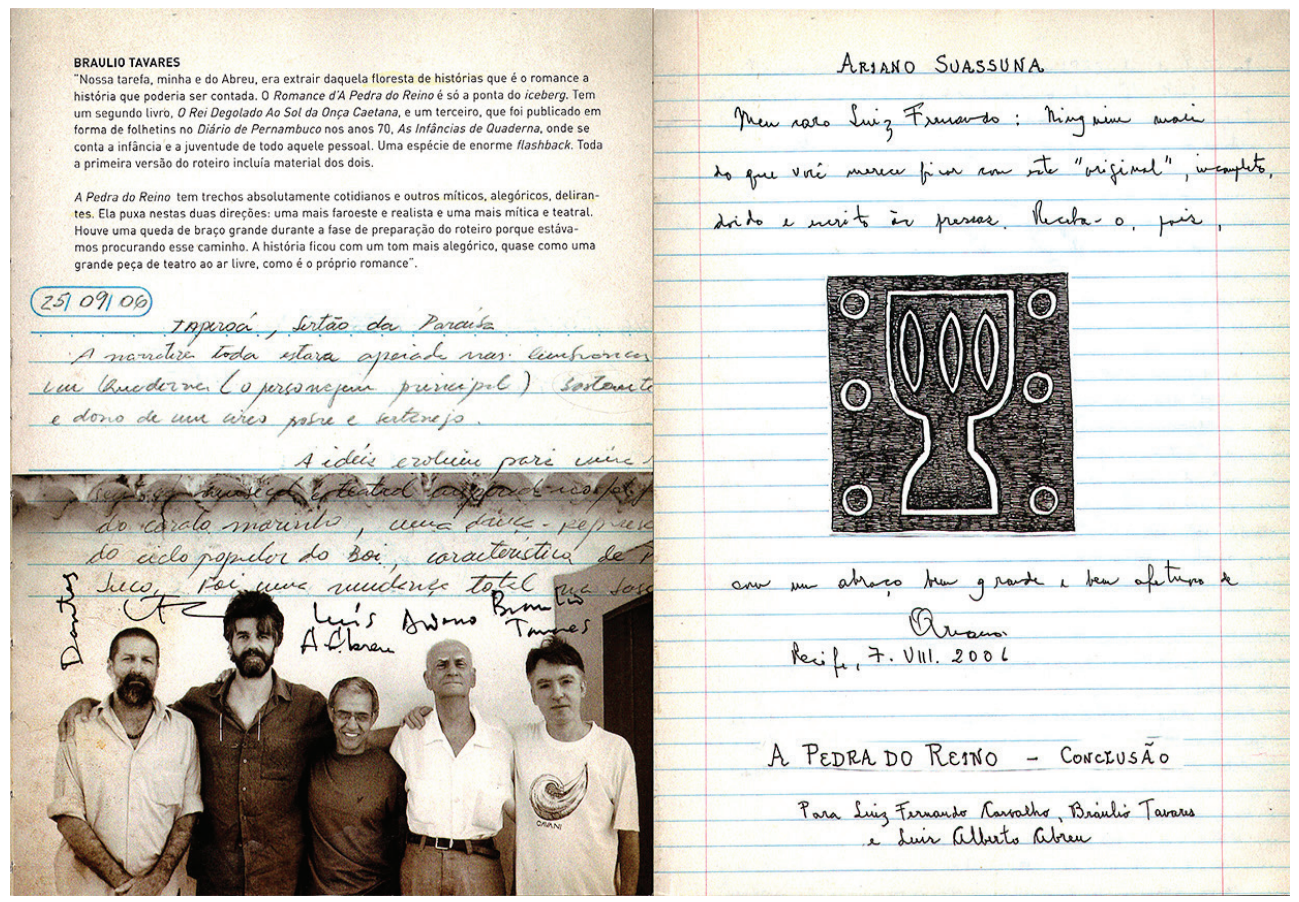

Figura 1. Carta de Suassuna para Carvalho presenteando o diretor com os manuscritos do livro Romance d Pedra do Reino e o príncipe do sangue do vai-e-volta. Suassuna com Luiz Fernando Carvalho e sua equipe criativa. Fonte: CARVALHO, 2007, v.6, s/p.

Nos livros de processo de Luiz Fernando Carvalho, tem-se um dossiê da produção organizado em um volume na forma de seis livros acondicionados em estojo ilustrado por Fernando Vilela .O estojo de livros de processo é composto por Livro 1: A Pedra do Reino, Livro 2: Os emparedados, Livro 3: Os três Irmãos Sertanejos, Livro 4: Os doidos, Livro 5: A demanda do Sagral, Livro 6: Diário de elenco e equipe.

O livro de processo seis é composto por registros do diretor, do elenco e da equipe produzido durante os períodos de ensaios e filmagens e ainda possui vários depoimentos do próprio Ariano Suassuna sobre seu livro Romance d' A pedra do reino (Figura 1).

Vale dizer que Suassuna acompanhou todo o trabalho da equipe de Carvalho, inclusive presenteando o diretor com os manuscritos incompletos do romance, como toma conhecimento o leitor por meio do sexto livro de processo. Nesse último volume, além de ilustrações, reprodu- ções de manuscritos de anotações diversas e depoimentos, há também o registro fotográfico dos ensaios, dos figurinos, da cidade cenográfica e das paisagens de Taperoá, cidade no sertão da Paraíba onde foi filmada a microssérie.

Para o escopo da reflexão aqui pretendida, nos interessa mais de perto o referido livro seis, voltado para registros de toda equipe, mas também nos valeremos de anotações importantes realizadas pelo diretor nos outros diários. Desse modo, nos interessa observar e discutir o trânsito entre as escolhas do diretor e as escolhas do grupo criativo envolvido na criação e realização da microssérie A pedra do Reino. Tomamos, pois, o livro de processos seis, em suas tessituras de ordem híbrida e suas dimensões permutáveis de significação, para pensar no campo relacional que se estabelece nas negociações de sentido de um projeto que parte do individual e se estabelece na feitura em grupo.

Ao pensar na produção audiovisual de uma 
Figura 2. Montagem de fotografias de participantes do processo criativo da microssérie. Fonte: CARVALHO, 2007, v.6, s/p.

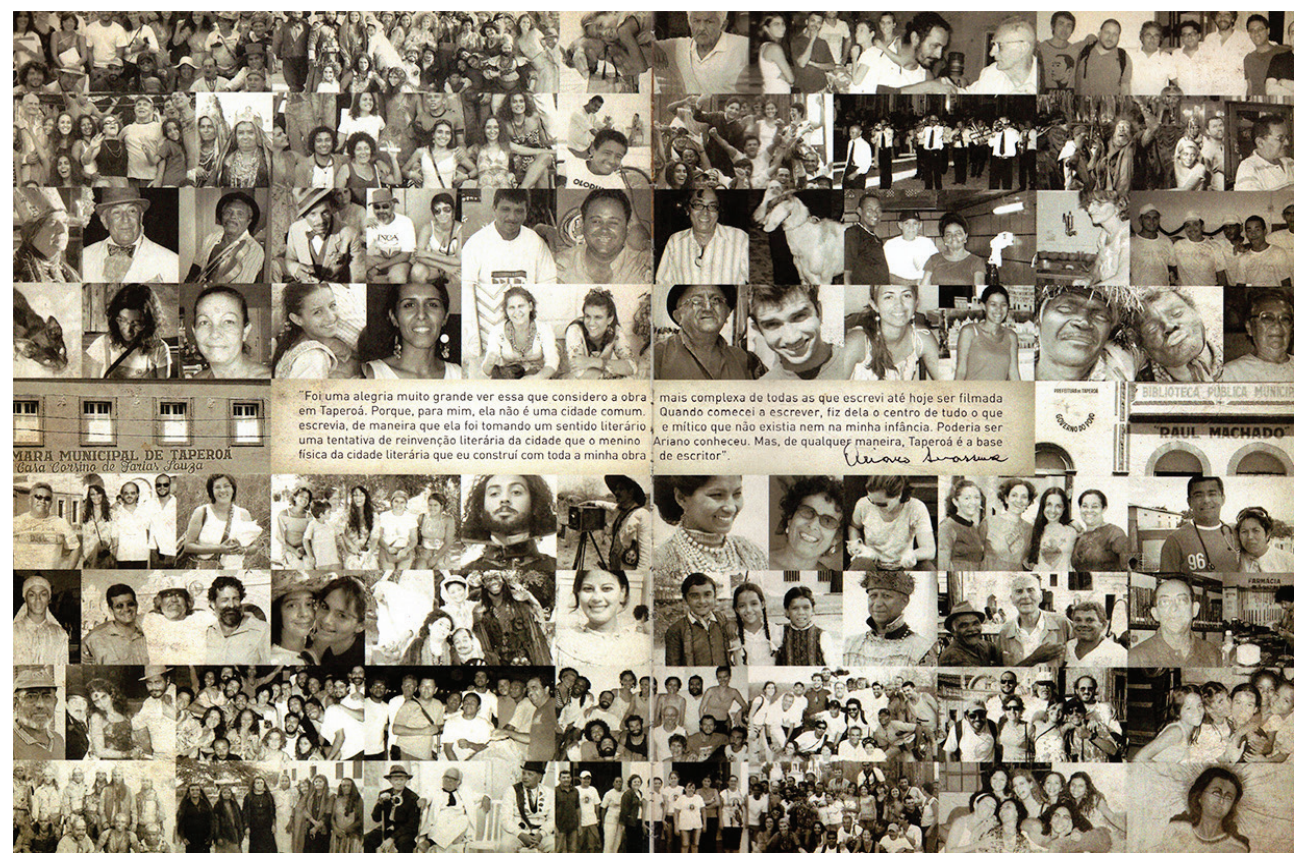

microssérie, sobretudo com os trânsitos intersemióticos instaurados na A pedra do Reino, tem-se a necessidade de compor uma equipe formada por pessoas com diferentes repertórios estéticos e técnicos: diretores, atores, iluminadores, montadores, figurinistas, diretores de fotografias, músicos, preparadores corporais, dentre outros. Não por acaso, a última página do diário coletivo apresenta uma bricolagem de imagens das pessoas envolvidas no processo de criação da microssérie, lembrando que, além da equipe criativa, muitos moradores da cidade de Taperoá, sertão da Paraíba onde foi filmada a obra, também participaram ativamente do processo como figurantes e na prestação de variados serviços, como será comentaremos um pouco mais adiante (Figura 2).

Importa, portanto, pensar como, em meio a um processo de natureza iminentemente coletiva, podemos também localizar a singularidade de um pensamento que de certo modo orienta toda essa esfera dialógica. Estamos aqui nos referindo ao projeto pessoal e artístico do diretor Luiz Fernando Carvalho que, como se evidencia no conjunto dos seis livros de processo, se debruçou sobre o projeto ético e estético de Ariano Suassuna, calcado em bases Armoriais ${ }^{4}$. O diretor é responsável, portanto, por formar e convocar sua equipe, estimulando o envolvimento pleno e o entusiasmo do grupo que passa também a partir das suas motivações a compreender e desejar o projeto artístico. Trata-se,

4 O Movimento Armorial, fundado nos anos 1970 por Ariano Suassuna, possui como formulação estética as referências às obras de artistas populares tomadas por escritores, músicos, artistas plásticos, teatrólogos, ceramistas e bailarinos como instrumentos de recriação de outras obras. As criações resultantes dessa reescritura podem não se situar exatamente na esfera do popular, como é o caso da produção literária do próprio Suassuna. Trata-se, na verdade, de um tratamento reciclante da cultura oral e popular nordestina - o folheto de cordel, a gravura, a cantoria, os espetáculos de marionetes, as danças populares - tomadas como matriz de uma nova organização estética que tem como preceito a busca da poética popular como base de criação, relacionando assim a produção popular e a erudita 

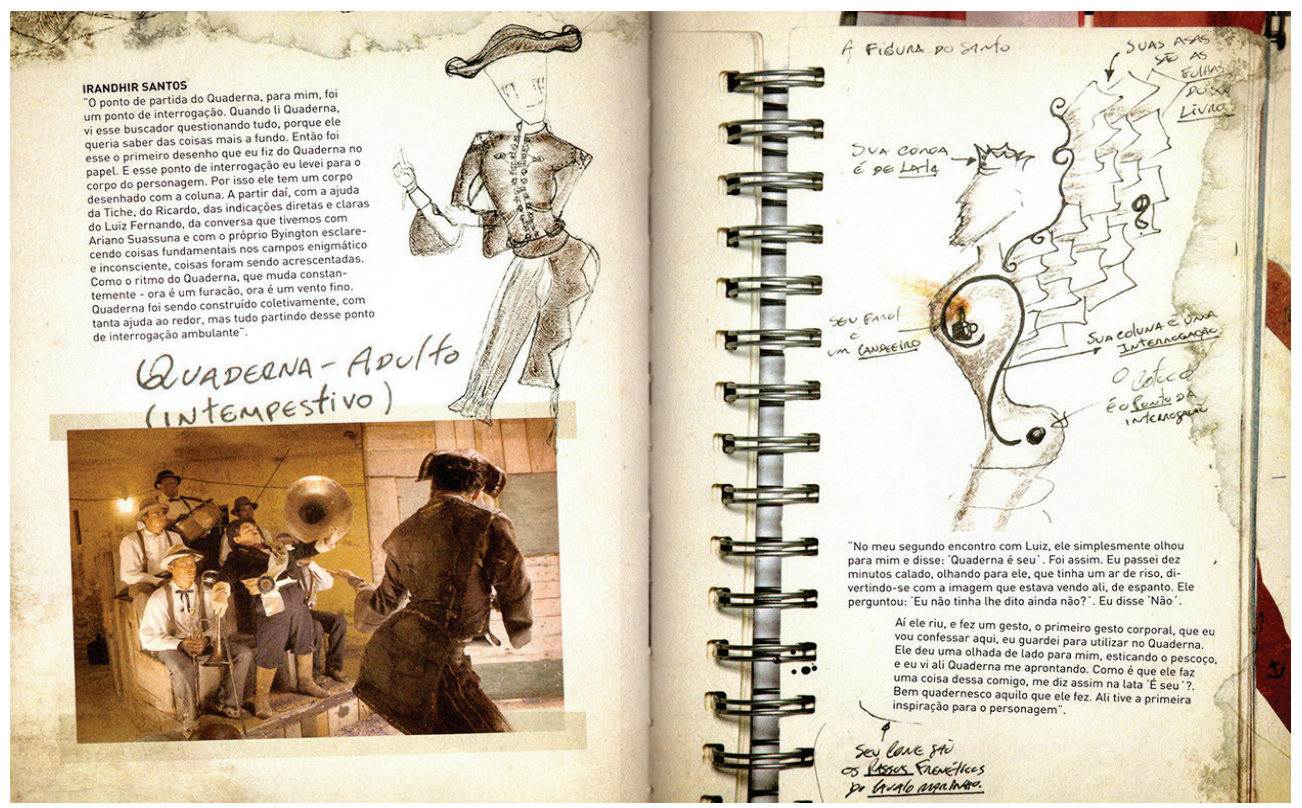

Figura 3. Registros do ator Irandhir Santos sobre a criação da personagem Quaderna. Fonte: CARVALHO, 2007, v.6, s/p.

conforme nos lembra Salles (2017) da função do líder, capaz de reunir esforços e desejos para a construção de um projeto que se torna comum:

O diretor, neste caso, é visto como uma liderança, que convoca para a realização de um projeto, por ele idealizado ou proposto; no entanto, esta equipe é formada por sujeitos, com seus próprios desejos e buscas. Ao mesmo tempo que o ator se coloca à disposição do projeto do diretor, ele quer estar muito bem neste papel, provavelmente, para atender a seu desejo individual. (Salles, 2017, p. 128)

Vejamos, neste sentido, a criação do personagem Quaderna, protagonista da microssérie, interpretado pelo ator Irandhir Santos que evidencia em seus registros verbo-visuais (Figura 3) as indicações precisas do diretor, a influência da equipe e as suas próprias decisões em relação ao personagem em seus vários níveis: físico, emotivo e até mesmo inconsciente.

O ponto de partida do Quaderna, para mim, foi um ponto de interrogação. Quando li Quaderna, vi esse buscador questionando tudo, porque ele queria saber das coisas mais a fundo. Então foi esse o primeiro desenho que eu fiz do Quaderna no papel. E esse ponto de interrogação eu levei para o corpo do personagem. Por isso ele tem um corpo desenhado com a coluna. A partir daí, com a ajuda da Tiche, do Ricardo, das indicações diretas e claras do Luiz Fernando, das conversas que tivemos com Ariano Suassuna e com o próprio Byington esclarecendo coisas fundamentais nos campos enigmático e inconsciente, coisas foram sendo acrescentadas. Como o ritmo do Quaderna, que muda constantemente - ora é um furação, ora um vento fino. Quaderna foi sendo construído coletivamente, com tanta ajuda ao redor, mas tudo partindo desse pon-

to de interrogação ambulante. ${ }^{5}$

Em muitos outros registros do livro de processo coletivo, evidencia-se a importância das escolhas pessoais dos atores na composição de seus personagens. No entanto, como adverte Irandhir Santos, sempre com indicações "diretas e claras" do diretor que parece, por sua vez, ab-

5 SANTOS. In: Carvalho. Diário de elenco e equipe. s/p. 
Figura 4. Registros do ator Caca Carvalho sobre a experiência coletiva de criação. Fonte: CARVALHO, 2007, v.6, s/p.

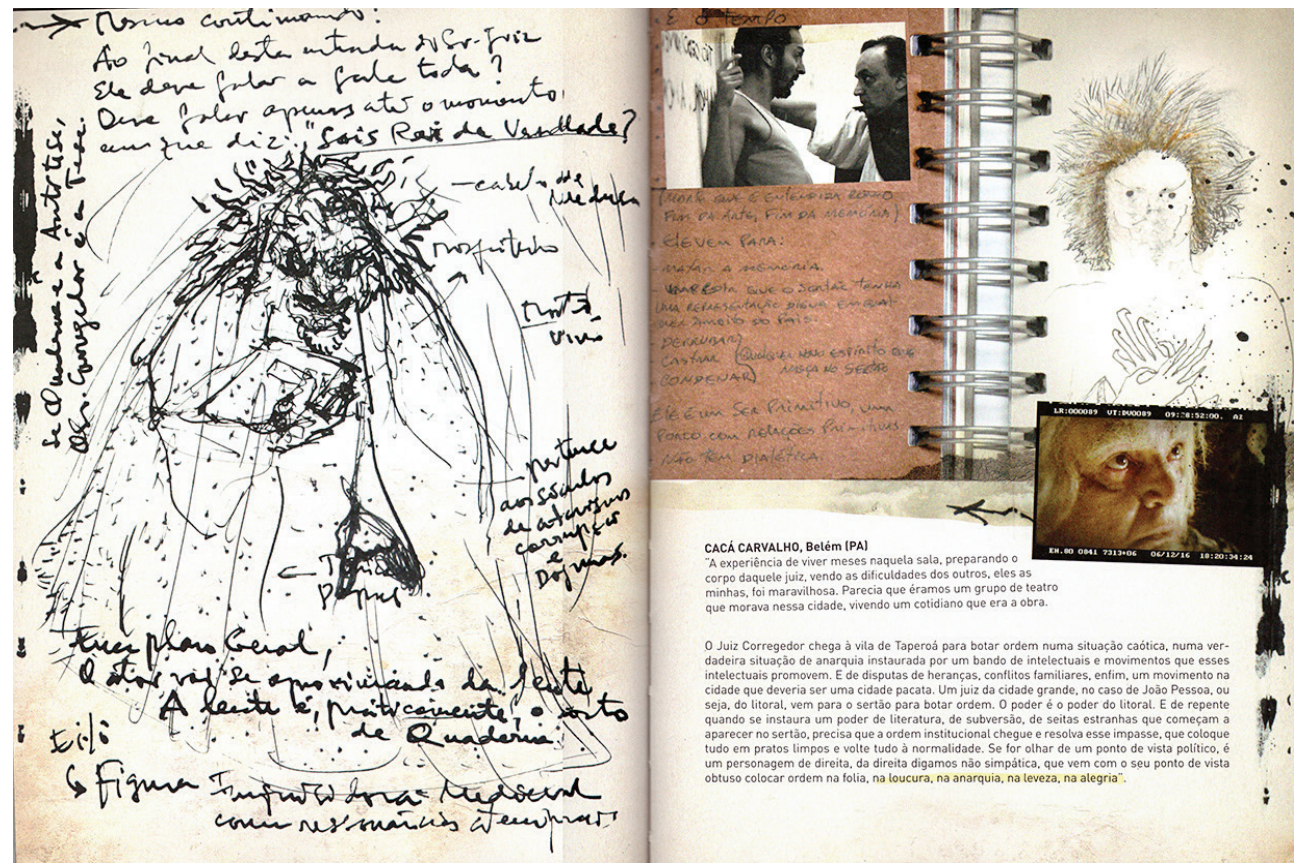

sorver a liberdade de pensamento e de expressão do grupo como um todo. Um aspecto muito importante do processo criativo da microssérie foi a mudança, meses antes das filmagens, do grupo para a cidade de Taperoá 6 , localizada no coração da Paraíba, onde nasceu Ariano Suassuna. O diretor desejou criar um processo de trabalho a partir de talentos locais. Assim, com a chegada do grupo, artesãos, costureiras, pintores, pedreiros, marceneiros, cozinheiras, auxiliares gerais e outros moradores, cerca de 300 pessoas, foram envolvidas no projeto. Foi desse

6 A esse respeito vale enfatizar um trecho de fala de Ariano Suassuna a respeito das filmagens em Taperoá, transcrita para o diário seis. "Foi uma alegria muito grande ver essa que considero a obra mais complexa de todas as que escrevi até hoje ser filmada em Taperoá. Porque, para mim, ela não é uma cidade comum. Quando comecei a escrever, fiz dela o centro de tudo o que escrevia, de maneira que ela foi tomando um sentido literário e mítico que não existia nem na minha infância. Poderia ser uma tentativa de reinvenção literária da cidade que o menino Ariano conheceu. Mas, de qualquer maneira, Taperoá é a base física da cidade literária que eu construí com toda a minha obra de escritor". modo que a Secretária de Saúde da cidade virou o ateliê do figurino, o refeitório foi instalado na Secretaria de Educação, a casa onde Ariano Suassuna morou na infância foi ocupada pela equipe de arte e o antigo armazém de algodão se transformou no galpão de ensaios.

Essa imersão no espaço e tempo do sertão foi muito significativa para o envolvimento do grupo criativo como um todo no projeto. Palavras como intensidade, entrega, inovação, trocas, vivências e outras que enfatizam a força desse processo criativo aparecem nos registros dos atores que passam a "respirar" o universo armorial, traduzido da obra de Suassuna para a linguagem do audiovisual. "A obra de Ariano, o Cariri Paraibano e a magia do processo conduzido pelo Luiz Fernando nos arrebatou. Os exercícios foram decisivos na composição dos personagens", anotou o ator Jones de Melo. No galpão, própria na entrega plena à dicção da obra de os atores foram encontrando sua linguagem 


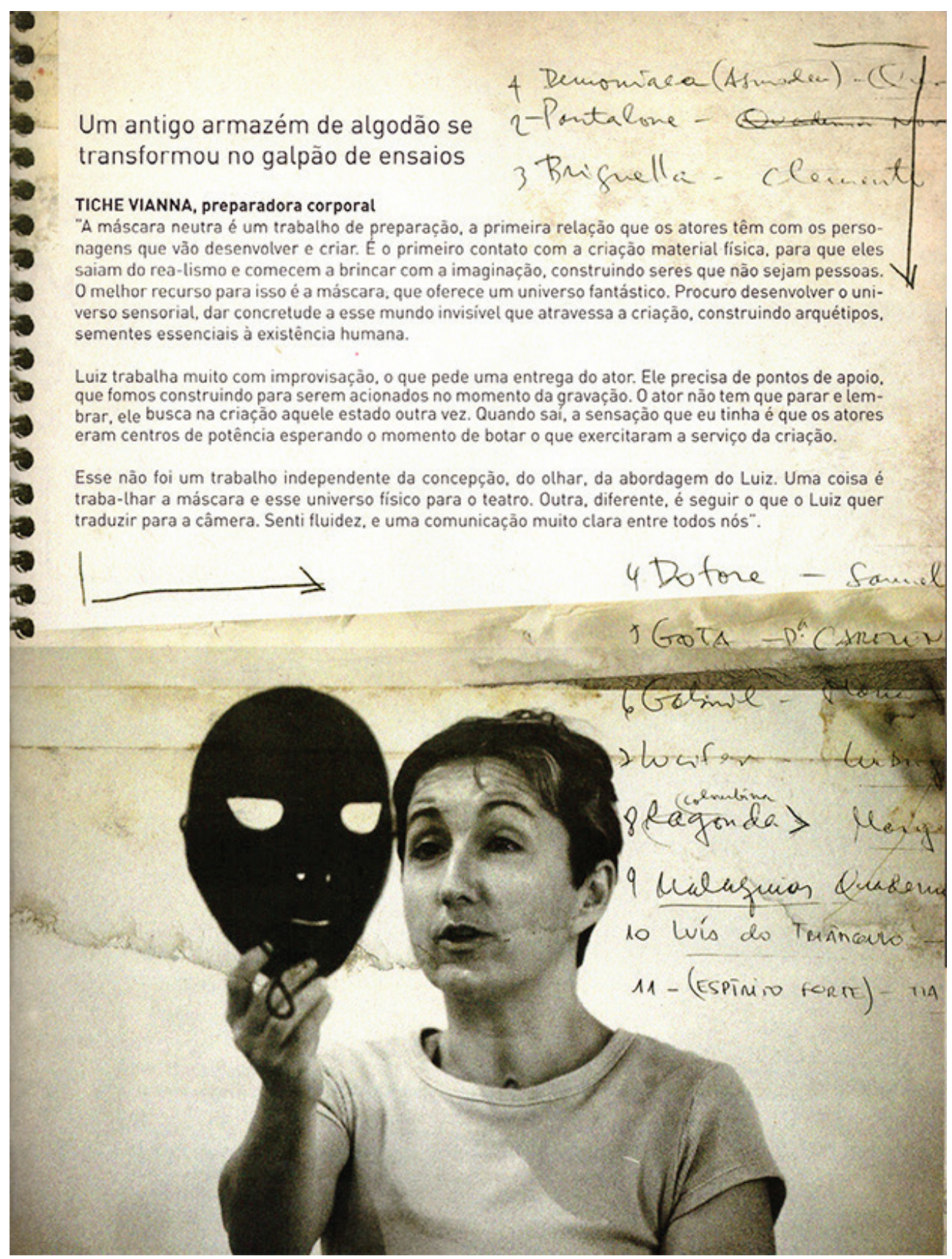

Figura 5. Registros de Tiche Viana sobre direcionamentos de Carvalho na preparação do elenco. Fonte: CARVALHO, 2007, v.6, s/p. 
origem como registrou Cacá Carvalho (Figura 4.), que interpretou o personagem do Juiz Corregedor. "A experiência de viver meses naquela sala, preparando o corpo daquele juiz, vendo as dificuldades dos outros, eles as minhas, foi maravilhosa. Parecia que éramos um grupo de teatro que morava nessa cidade, vivendo um cotidiano que era a obra".

Essa profunda entrega do grupo que, no galpão ia sendo tomado pelo universo Armorial não aconteceu, no entanto, a deriva do diretor. Todos os artistas envolvidos estavam, de certo modo, sendo conduzidos por seu olhar criativo. Como propositor do projeto, apresentava tomadas de decisão nos processos colaborativos, como se evidencia, por exemplo, no registro de Tiche Vianna, preparadora corporal do elenco (Figura 5).

Luiz trabalha muito com improvisação, o que pede uma entrega do ator. Ele precisa de pontos de apoio, que fomos construindo para serem acionados no momento da gravação. $O$ ator não tem que parar e lembrar, ele busca na criação aquele estado outra vez. Quando saí, a sensação que eu tinha é que os atores eram centros de potência esperando o momento de botar o que exercitaram a serviço da criação. Esse não foi um trabalho independente da concepção, do olhar, da abordagem do Luiz. Uma coisa é trabalhar a máscara e esse universo físico do teatro. Outra, é diferente, é seguir o que o Luiz quer traduzir para a câmera. Senti fluidez, e uma comunicação muito clara entre todos nós. 7

Os registros da equipe criativa apontam para certas reflexões que emergem para o ato de uma criação coletiva guiada por princípios direcionadores pensados por um sujeito, nesse caso, o diretor, que absorve as contribuições de todo o grupo num fluxo de criação gerador de novos "nós" a cada manifestação dos membros participantes

7 VIANA. In: CARVALHO. Diário de elenco e equipe. s/p do projeto. Estamos no terreno de uma autoria porosa, aberta às relações que se formam na rede construída permanentemente no processo de criação. A esse respeito, ressalta Salles:

A partir dessas questões, vejo os agentes em criação em meio à multiplicidade de interações e diálogos - sujeitos constituídos e situados - que encontraram modos de manifestação em brechas que seus filtros mediadores conquistaram. O próprio sujeito tem a forma de uma comunidade; a multiplicidade de interações não envolve absoluto apagamento do sujeito e o locus da criatividade não é a imaginação de um indivíduo. Proponho, assim, um conceito de autoria, exatamente nessa interação entre o sujeito e os outros. É uma autoria distinguível, porém não separável dos diálogos com o outro; não se trata de uma autoria fechada em um sujeito, mas não deixa de haver espaço de distinção. Sob esse ponto de vista, a autoria se estabelece nas relações, ou seja, nas interações que sustentam a rede que vai se construindo ao longo do processo de criação. Trata-se do conceito de autoria em rede. (SALLES, 2017, 39-40)

Nesse sentido, pontos centrais da definição de rede, como a ideia de que a rede é uma estrutura composta de elementos em interação, o entendimento de que a rede é uma estrutura de interconexão instável em constante movimento e também a compreensão de que sua modificação obedece a uma regra básica de funcionamento, mesmo que tal regra seja modelizável, serão importantes para compreender a impossibilidade de estabelecer qualquer linearidade em processo de criação, sobretudo os que envolvem equipes.

Por essa via de raciocínio, para Salles, a necessidade de abordar o processo criativo com o auxílio da metáfora da rede parte, sobretudo, do entendimento de que o ato de criação possui natureza complexa e, por isso mesmo, relacional. Nesse sentido, muitas vezes, os documen- 
tos de processo de um artista incorporam uma diversidade de signos ativando relações que levam o pesquisador a se estabelecer em pleno campo relacional:

Estarei dando destaque especial à necessidade de se pensar nosso objeto de estudo no contexto da complexidade, o que implica romper o isolamento dos objetos ou sistemas, impedindo sua descontextualização e ativando as relações que os mantêm como sistemas complexos (SALLES, 2006, p.85)

Um segundo argumento de Salles, para trabaIhar com a noção de rede como operadora de leitura de documentos de processos, é pautado na semiótica peirceana no que tange o conceito básico de semiose. Conceito esse que parte da noção de que um signo só adquire sentido em relação a outros signos que participam de um dado contexto enunciativo. Isso significa dizer que a incompletude é inerente ao signo e que o sentido de um texto somente poderia ser construído em rede.

O ato criador como processo sígnico aparece como um processo inferencial no qual toda ação, que dá forma ao novo sistema, está relacionada a outras ações de igual relevância, ao se pensar o processo como um todo. Uma decisão do artista tomada em determinado momento tem relação com outras anteriores e posteriores. Do mesmo modo, a obra vai se desenvolvendo por meio de uma série de associações ou estabelecimento de relações. A anotação no guardanapo do bar não é nada mais, muitas vezes, do que a tentativa de não deixar uma associação se perder. (SALLES, 2006, p.85)

Um ponto importante que evidencia a coerência da abordagem do movimento criador como uma "complexa rede sígnica de inferências" é a ideia de não linearidade, ponto fulcral da visualidade da rede. Não se avança na reflexão sobre processos criativos, desconsiderando ramificações. Trata-se mesmo da imagem de um diagrama em rede que nos parece tão oportuna para se pensar projetos de processos em equipe:

Um diagrama em rede é constituído, em um dado instante de uma pluralidade de pontos (picos) ligados entre si por uma pluralidade de ramificações (caminhos), um pico é a interseção de vários caminhos e, reciprocamente, um caminho põe em relação vários picos. A árvore torna-se um caso particular ou uma variante de rede, ou seja, um encaminhamento a partir de um determinado pico, enquanto a rede oferece sempre a possibilidade de vários caminhos. (MUSSO, 2004, p.17)

É no plano, portanto, das interseções que que podemos pensar um movimento criativo em rede, formado por complexas interações não lineares. Assim, não interessa a ideia de origem do processo criativo, tão pouco desvendar um percurso de modo fidedigno ao que o artista pensou para seu gesto criativo, até mesmo porque, no âmbito da criação em processos de equipe, esta tarefa seria mesmo impossível. O importante são as conexões não lineares que se apresentam ao olhar inquieto do pesquisador, em busca de índices do processo criativo que se estabelecem nos documentos de processos coletivos que circundam a criação de uma obra.

Ao pensar, portanto, nas singularidades do rico processo de criação que envolveu a equipe da A pedra do reino, devemos lembrar de alguns "nós" fundamentais para a sustentação estética da produção audiovisual. Estamos nos referindo ao movimento tradutório da obra de Ariano Suassuna, sendo este movimento criativo, conduzido, portanto, por um jogo intertextual. Interessa-nos a apreensão do movimento tradutório intersemiótico ainda em processo, buscando interpretar pontos importantes da tradução - ainda sob a ordem do inacabado - do 
romance de Suassuna aos elementos narrativos da microssérie pensada aqui no seu domínio também coletivo de produção.

Como já dito, a microssérie é uma tradução da obra maior, do escritor paraibano Ariano Suassuna, Romance d' Pedra do Reino e o príncipe do sangue do vai-e-volta. Nesse livro, seguindo a base de sua criação artística, Suassuna instaura uma narrativa que, com uma singular sintaxe textual, transita entre referências populares e eruditas para fazer emergir o sertão, liberto de sua condição regional. Nessa complexa tessitura híbrida de gêneros, as referências a obras populares - cantos improvisados, danças populares, poemas de cordel, espetáculos de marionetes, dentre outras manifestações orais ou escritas da cultura popular nordestina - são absorvidas como signo do processo criativo de Suassuna. Forma-se uma rede de escrituras em que, ao material popular, são agregadas as leituras do vasto repertório do escritor: autores de ficção, dramaturgos e filósofos clássicos como, por exemplo, Cervantes, Euclides de Cunha, José de Alencar, Frederico Gárcia Lorca, Gil Vicente, Nietzsche, dentre outros.

O texto de Suassuna assume uma narrativa em movimento que se alimenta de fontes variadas em um processo constante de manifestações intertextuais que, organizadas pela imaginação do autor, constroem uma narrativa singular. Assim, o processo em equipe da microssérie segue uma tessitura ainda mais complexa já que o processo criativo de Carvalho advêm do movimento criador de outra obra - o romance de Suassuna - que, por sua vez, se organiza em torno de outros processos tradutórios - as recriações de obras populares e também conteúdos de repertórios de variadas linguagens.

Estamos, então, em pleno campo relacional em que uma complexa rede sígnica nos leva a inferir o desenvolvimento da microssérie de Carvalho por meio de uma série de associações ou estabelecimento de relações. Nesse espaço relacional, entre a obra literária original e a obra audiovisual tradutora, se instaura, pois, um movimento criativo tradutório. Ao pesquisar o processo criativo da microssérie A pedra do Reino, tomando os livros de processo como documentos de processo, além de outras fontes genéticas como entrevistas concedidas por Carvalho e também por Suassuna, fica evidenciado que o diretor fez um mergulho profundo e minucioso no universo suassuniano como um todo ${ }^{8}$, buscando se aproximar dos signos que regem as referências populares tomadas pelo escritor. Como resultado, podemos dizer que Carvalho, em sua operação tradutora, assimilou a "formação ínsita do original", para usar uma expressão de Haroldo de Campos. Ou seja, o diretor buscou o modus operandi do romance de Suassuna assimilando a gênese do original para só então realizar a tradução intersemiótica. Como esse modo de formar, no caso da obra de Suassuna, passa pelas premissas armoriais, Carvalho buscou efeitos novos ou variantes em sua versão televisiva autorizados pelo original na sua linha de invenção. Para além do romance, o diretor trouxe à tona em sua microssérie a ambiência criativa de Suassuna, tocando em seu ponto tangencial, qual seja, as referências

80 diálogo artístico entre Suassuna e Carvalho vem de longa data e teve início com adaptações que o diretor realizou de duas peças teatrais do autor. Uma mulher vestida de sol (1994), primeira incursão de Suassuna na dramaturgia, foi adaptada por Carvalho em 1994 num especial televisivo na Rede Globo. A estrutura teatral foi claramente mantida por meio do cenário e da iluminação que evidenciavam se tratar de uma reprodução não naturalista. A farsa da boa preguiça, peça de Suassuna de 1960, foi ao ar em 1995 também na Rede Globo e também evidenciou a referência ao teatro popular nordestino, sobretudo no cenário pouco afeito à reprodução mimética almejada pelo padrão de microsséries e novelas da emissora. 


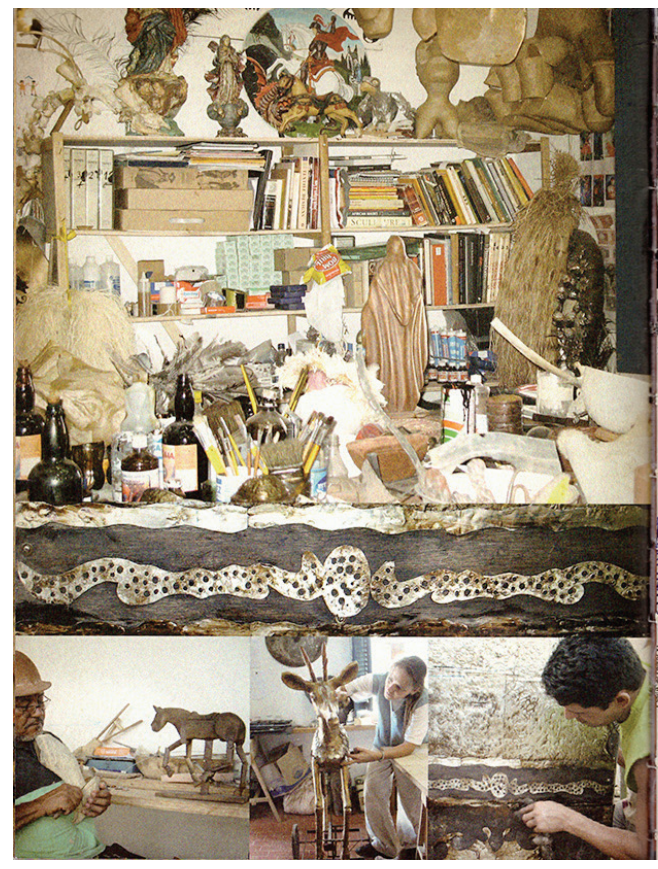

bases da criação do escritor que passam, necessariamente, pelas referências da cultura oral e popular do nordeste.

Essa ambiência armorial foi, portanto, a base de criação de todo o grupo envolvido na microssérie. Não se pode pensar em equipe criativa, sem observar como cada sujeito envolvido no processo coletivo assimilou, no caso da microssérie A pedra do Reino, as bases armoriais que a guiaram e foram tomada pelo diretor como princípios norteadores do processo criativo da equipe, considerando a interpretação que o grupo realizou da estética armorial.

Não seria possível dentro da extensão desse artigo mensurar todas as traduções realizadas pela equipe envolvida na microssérie acerca desse fio condutor escolhido pelo diretor como eixo criativo para o qual todas as decisões do grupo deveriam ser conduzidas. Só para dar alguns exemplos, no livro de processo da equipe, é possível vislumbrar escolhas no campo musical tomando a figura do cantador, uma vez

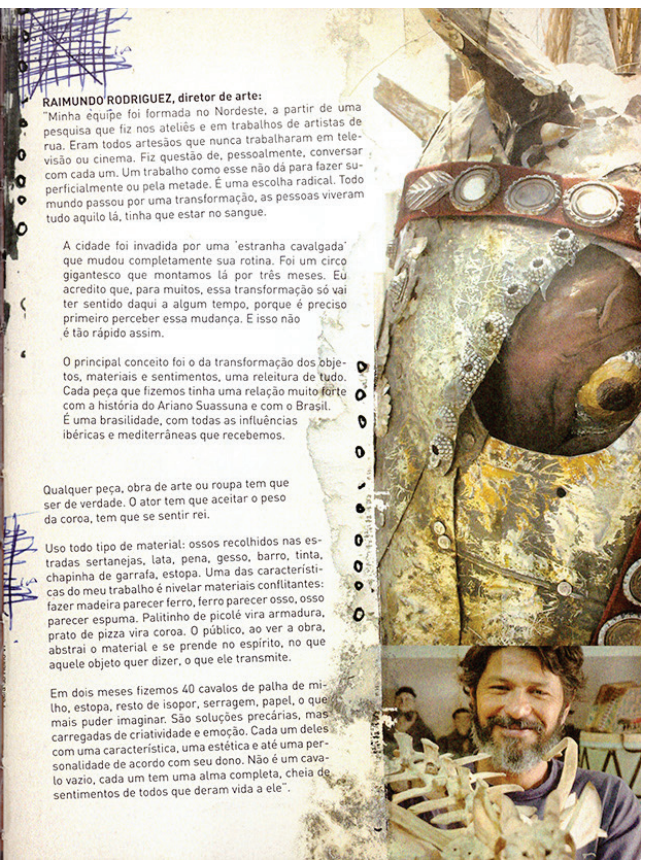

Figura 6. Registros de Raimundo Rodrigues sobre a direção de arte da microssérie utilizando elementos da estética armorial. Fonte: CARVALHO, $2007, v .6, s / p$. que a música sertaneja é uma das bases armoriais. Na direção de arte, temos registros da opção de Raimundo Rodrigues (Figura 6), responsável pela direção artística da microssérie, por usar bonecos no lugar de animais, reforçando a alusão ao teatro popular nordestino, fazendo menção também aos mestres mamulengueiros e seus bonecos, importantes referências do teatro armorial.

Pelo livro de processo da equipe, temos acesso, portanto, ao modo pelo qual parte significativa da equipe envolvida no processo assimilou as referências diversas de linguagens e repertórios estéticos advindos do universo Armorial. A inserção do olhar de cada membro da equipe para o esse universo permitiu a expansão da complexidade, estabelecendo novos "nós", novas conexões e arranjos tradutórios.

A leitura dos documentos de processos coletivos, mostrou que a equipe estava comprometida com um projeto comum e como nos lembra Salles (2017) "com a construção de princípios di- 
recionadores no contexto da coletividade". Isso significa pensar que é possível vislumbrar, na complexidade dos processos em equipe ou grupo, o olhar ou marcas de subjetividade de quem se coloca no lugar de mediador ou condutor do processo. De todo modo, o interesse desse lugar individual só se faz significativo, nos processos colaborativos, quando pensados também no modo de ação do coletivo.

Assim, para o pesquisador interessado na investigação do processo de criação coletiva cabe pensar nos nós que compartilhados não amarram pontos de significação, pois sempre há possibilidade de mais um laço.

\section{Referências}

CAMPOS, Haroldo de. Haroldo de Campos Transcriação. Organização de Marcelo Tápia e Thelma Médici Nóbrega. São Paulo: Perspectiva, 2013.

PARENTE, André (org.). Tramas da rede: novas dimensões filosóficas, estéticas e políticas da comunicação. Porto Alegre: Sulina, 2004.

SALLES, Cecília Almeida. Redes de criação: construção da obra de arte. Vinhedos: Horizonte, 2006.

SALLES, Cecília Almeida. Processos de Criação em Grupo: diálogos. São Paulo: Estação das Letras e Cores, 2017.

SUASSUNA, Ariano. A pedra do reino/da obra de Ariano Suassuna. Cadernos de filmagem do diretor (v.1,2,3,4,5). Escrito por Luiz Fernando Carvalho. Diário de elenco e equipe. Escrito por Luiz Fernando Carvalho e outros. São Paulo: Globo, 2007. 